\title{
Systematic review of prehospital haemostatic dressings
}

\author{
Matthew Welch (10, ${ }^{1}$ J Barratt, ${ }_{1}^{2}$ A Peters, ${ }^{3}$ C Wright $^{2}$
}

- Additional material is published online only. To view please visit the journal online (http://dx.doi.org/10.1136/ jramc-2018-001066)

${ }^{1}$ OUCAGS, University of Oxford, Oxford, UK

${ }^{2}$ Emergency Department, St Mary's Hospital Foundation Trust, London, UK ${ }^{3}$ Severn Valley Academic Foundation Programme, Southmead Hospital, Bristol, United Kingdom

\section{Correspondence to} Matthew Welch, University of Oxford, Oxford OX1 1DW, UK; matthew.welch1@nhs.net

The study has appeared in poster form at the RSM Colt Foundation Military Research Meeting.

Received 11 September 2018 Revised 3 January 2019 Accepted 10 January 2019 Published Online First 2 February 2019

\begin{abstract}
Introduction Haemorrhage is one of the leading causes of battlefield and prehospital death. Haemostatic dressings are an effective method of limiting the extent of bleeding and are used by military forces extensively. A systematic review was conducted with the aim of collating the evidence on current haemostatic products and to assess whether one product was more effective than others.
\end{abstract}

Methods A systematic search and assessment of the literature was conducted using 13 health research databases including MEDLINE and CINAHL, and a grey literature search. Two assessors independently screened the studies for eligibility and quality. English language studies using current-generation haemostatic dressings were included. Surgical studies, studies that did not include survival, initial haemostasis or rebleeding and those investigating products without prehospital potential were excluded.

Results 232 studies were initially found and, after applying exclusion criteria, 42 were included in the review. These studies included 31 animal studies and 11 clinical studies. The outcomes assessed were subject survival, initial haemostasis and rebleeding. A number of products were shown to be effective in stopping haemorrhage, with Celox, QuikClot Combat Gauze and HemCon being the most commonly used, and with no demonstrable difference in effectiveness.

Conclusions There was a lack of high-quality clinical evidence with the majority of studies being conducted using a swine haemorrhage model. Iterations of three haemostatic dressings, Celox, HemCon and QuikClot, dominated the studies, probably because of their use by international military forces and all were shown to be effective in the arrest of haemorrhage.

Topical haemostatics are bandages containing active ingredients used to stop bleeding in areas of the body where other methods, such as tourniquets, cannot be used. They are especially useful in prehospital medicine and there is evidence from animal experiments and clinical experience to show they work more effectively than standard gauze bandages. There are three major brands, Celox, QuikClot and HemCon, which dominate the literature around haemostatics. It is not clear from the evidence available if one of these brands is more effective than another.

employer(s)) 2020. No commercial re-use. See rights and permissions. Published by BMJ.

To cite: Welch M, Barratt J,

Peters A, et al.

BMJ Mil Health

2020;166:194-200.
In the developed world trauma is a leading cause of preventable death in those aged 44 years and under, and kills even more in resource-poor settings. ${ }^{12}$

\section{INTRODUCTION}

\section{Key messages}

Summary of contemporary evidence for topical haemostatics.

- A number of haemostatics have been shown to be effective in preclinical and clinical studies.

- There is considerable evidence for Celox, QuikClot and HemCon brands of haemostatic but little evidence to differentiate between them.

Haemorrhage following trauma is the highest cause of potentially survivable death on the battlefield and second in prehospital civilian trauma. ${ }^{3-6}$ Recent experience from Iraq and Afghanistan showed that deaths in potentially survivable injury were predominantly due to catastrophic haemorrhage (80\%). ${ }^{7}$ With recent terrorist attacks in the UK and elsewhere, this is becoming an increasingly important area of civilian prehospital medicine. ${ }^{8-11}$

Tourniquets are first-line treatment for major haemorrhage in the military setting, ${ }^{12} 13$ but are not effective at controlling junctional haemorrhage, in areas such as the groin, shoulders or neck. Surgical control of bleeding is, for the most part, highly impractical and unlikely on the battlefield or in the prehospital setting, whereas haemostatic dressings have been shown to be effective in these situations. They have thus been used by military forces with growing frequency over the last two decades, especially in conflicts in Iraq and Afghanistan.

A number of studies have shown prehospital haemostatics to be effective in haemorrhage control. ${ }^{14-20}$ Current-generation haemostatics have two main mechanisms of action: clotting factor activators and adhesive agents. Clotting factor activators initiate the intrinsic pathway of coagulation triggering clotting and include Kaolin, an inert mineral found in the QuikClot brand of haemostatics. Adhesive agents form a physical barrier to bleeding at the wound site by surface bonding of red blood cells to form an adhesive plug. Chitin, a polymer primarily derived from the shells of shellfish, is an adhesive agent found in the Celox and HemCon types of haemostatics. Previously, factor concentrator type of haemostatics was available such as Zeolite, a volcanic material which caused exothermic water absorption and thus concentration of clotting factors promoting coagulation. These were discontinued partially due to a concern over burns from the intense exothermic reaction. 
Through consensus it has been derived that the ideal haemostatic dressing has an extensive list of proposed properties, ${ }^{21} 22$ including:

- Is approved by the national drug and medical device governance.

- Stops severe arterial and/or venous bleeding in $<2 \mathrm{~min}$.

- Is effective on junctional wounds not amenable to a tourniquet.

- Is flexible enough to fit complex wounds and is easily removed without leaving residues.

- Has no toxicity or side effects.

- Causes no pain of thermal injury.

- Poses no risk to medics.

- Is ready to use and requires little or no training.

- Is durable and lightweight.

- Is stable and functional at extreme temperatures $(-10 \mathrm{c}$ to +40 c) for at least 2 weeks.

- Is practical and easy to use under austere conditions (low visibility, rain, wind, and so on).

- Has a long shelf-life, $>2$ years.

- Is inexpensive and cost-effective.

- Is biodegradable and bioabsorbable.

The accepted method of testing the efficacy of haemostatic dressings has been described by Kheirabadi and colleagues. ${ }^{22}$ This is a swine model with a $6 \mathrm{~mm}$ punch femoral arteriotomy with $30 \mathrm{~s}$ of free bleeding before a haemostatic dressing is applied with pressure for $2 \mathrm{~min}$ and fluid resuscitation started. Survival, initial haemostasis, rebleeding and post-treatment blood loss are all outcomes suggested for use in the model. Variations of this are used in the vast majority of studies assessing haemostatic dressings and are the industry standard.

The aim of this systematic review is to compare prehospital haemostatic dressings; to collate and analyse the contemporary evidence for their use, in order to define the most effective agent(s) for use in the combat and civilian, prehospital settings.

\section{METHODS}

A systematic search of the literature was conducted by the authors in accordance with the Preferred Reporting Items for Systematic Reviews and Meta-Analyses ${ }^{23}$ protocols available at: http://www.prisma-statement.org/

On 8 March 2016, the following databases were systematically searched by the Ministry of Defence librarians:

- MEDLINE

- CINAHL.

- EMBASE.

- AMED.

- ProQuest Hospital Collection.

- NHS Healthcare Databases Advanced Search to search AMED.

- British Nursing Index.

- CINAHL.

- EMBASE.

- HMIC.

- PsycINFO.

- Health Business Elite.

Databases were all searched for English language papers using the search terms in Box 1:

A search of the grey literature and wider internet was also performed by the defence librarians and authors. Manufacturers were contacted to provide study information and clarify technical information about their products.

\section{Box 1 Search strategy and terms used}

Haemostatic OR hemostatic OR celox OR quikclot OR hemcon OR chitosan OR chitogauze OR combat gauze

AND

Prehospital OR battlefield OR military OR ambulance OR swine OR animal OR combat

AND

Survival OR haemostasis OR re-bleeding OR blood loss OR efficacy

The abstracts of studies found by the systematic search were examined independently by two of the authors against the criteria for inclusion listed in Box 2. The studies had to include a current-generation haemostatic and test outcomes of survival, initial haemostasis and/or rebleeding. Papers looking at surgicalspecific haemostatic interventions, deemed not to be applicable in the prehospital setting, were excluded, as were those looking at specialised methods of haemorrhage control (iTClamp, REBOA, new tourniquet devices, and so on), experimental compounds, or those unsuitable for use in the prehospital or battlefield environment.

If the assessing authors disagreed over the inclusion of a study then the paper was referred to the third author for final adjudication. Figure 1 shows the numbers and outcome of all the studies found in the initial search.

The studies were assessed against a defined hierarchy of study outcomes. Survival, then initial haemostasis, then rebleeding were used in order to define the efficacy and, if applicable, superiority of agents in head-to-head preclinical trials.

\section{RESULTS}

Forty-two studies from 2008 to 2015 met the final criteria to be included in the systematic review of papers. Of these, 31 were preclinical animal studies-predominantly swine arterial models, and the remaining were 11 studies looking at prehospital clinical uses: 7 from the battlefield, 3 from the civilian prehospital and 1 using a combination of both. A meta-analysis could not be performed due to the heterogeneity of methods and outcomes used in the studies, making them unsuitable for quantitative analysis.

\section{Preclinical studies}

In the preclinical studies, variations of the Kheirabadi ${ }^{22}$ swine model were used for the majority; this being the current standard for preclinical haemostatic studies. Goat, rat and sheep models were also used, as well as mixed bleeding models, looking at arterial and/or venous bleeding. There was variation in the lengths of time for free bleeding, the methods used for vessel puncture/transection, resuscitation methods and dressing application. The list of preclinical studies included, along with their outcome data, can be found in the online supplementary appendix 1 .

\section{Box 2 Inclusion criteria}

- Current-generation haemostatic.

- Prehospital deployable.

- Outcome of survival, initial haemostasis or rebleeding.

- Complete study obtainable.

- Not surgery specific. 


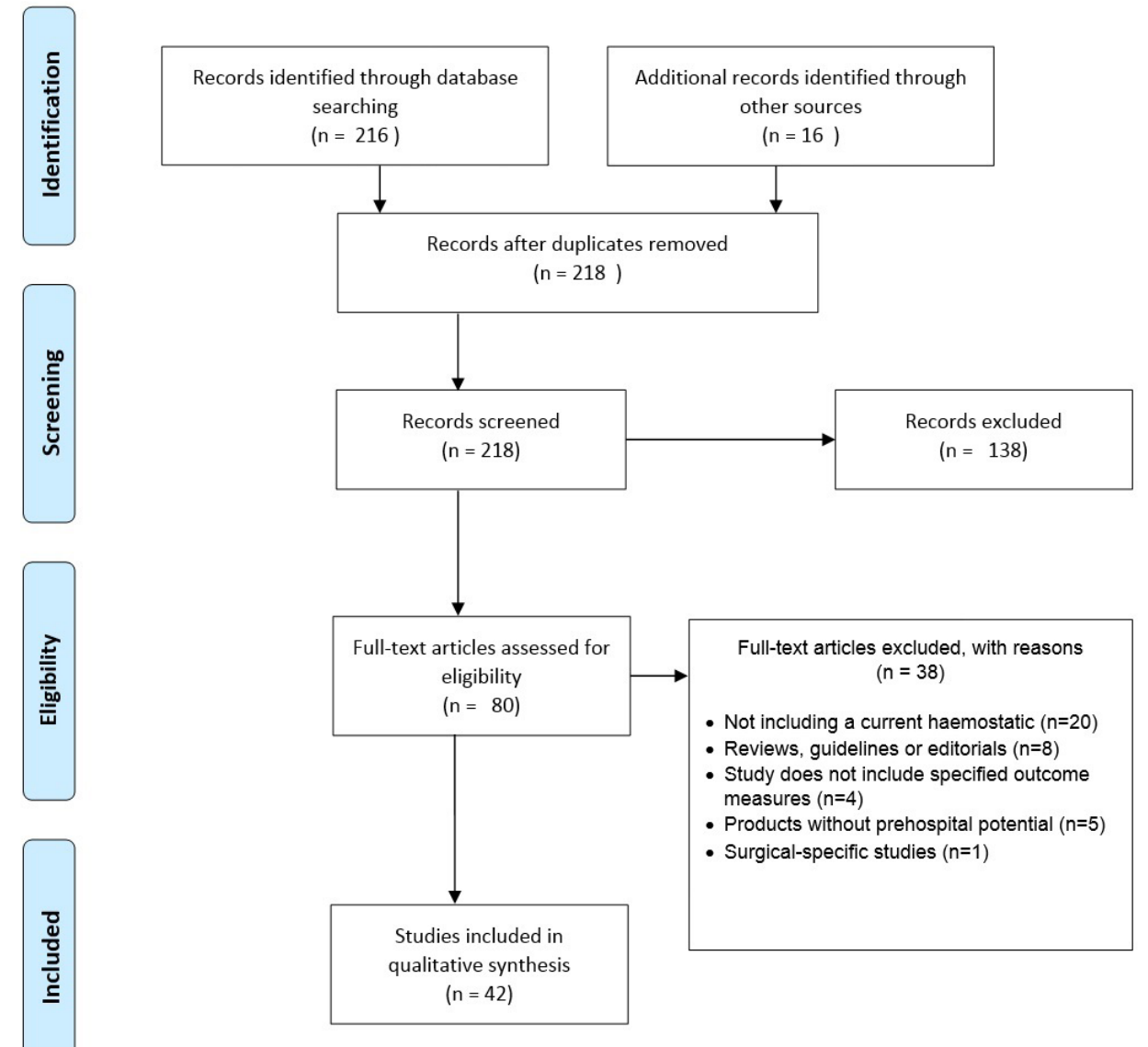

Figure 1 Preferred Reporting Items for Systematic Reviews and Meta-Analyses (PRISMA) diagram showing the path of all papers found in initial search. $^{23}$

\section{Clinical studies}

The 11 clinical studies ${ }^{24-34}$ were predominantly from uses of haemostatic dressings on the battlefield, with three studies of prehospital civilian uses and two combinations of battlefield and civilian use. In all of the studies the haemostatic agents used were found to be effective with high survival rates (79\%-93\%) and no serious adverse effects reported. All of the clinical studies used initial haemostasis as their primary endpoint, with several also including survival. Table 1 summaries the prehospital clinical studies.

There were multiple haemostatics used in the studies but there were three which were used overwhelmingly more than all others in both clinical and preclinical studies: HemCon, Celox and QuikClot Combat Gauze. The number of instances of use of these haemostatics is shown in Table 2.

Note that there have been multiple iterations and names of each of the main haemostatics but for the purposes of this study they have been combined into single groups, as the formulations have remained very similar. Further details have been included in the online supplementary appendix 2 .

Celox, HemCon and QuikClot dressings were shown to be effective at arresting haemorrhage in 17, 18 and 20 studies, respectively. This is summarised in Table 3 .

In the included studies, there were 11 that provided head-tohead competition between two or all three of the market-leading haemostatic dressings, using outcomes (in order) of survival, initial haemostasis and incidence of rebleeding. The results are shown in Table 4 and in Figure 2.
In Figure 2, underlined numbers are the total number of studies including this haemostatic. The numbers in one circle alone represent the products effective but not tested competitively. Head-to-head trials are shown in bold by overlap between competing products with the most effective product in that study listed. The middle shows the results of head-to-head trials featuring all three leading haemostatics.

\section{Safety}

There were no safety concerns among the products evaluated in this study. WoundStat was not included in this review, as it was removed from market due to safety concerns, particularly as regards multiple pulmonary emboli, ${ }^{15}$ and thus is not a current haemostatic. Previous incarnations of QuikClot using Zeolite were associated with some thermal injuries, ${ }^{35}{ }^{36}$ but the current version of the product (using Kaolin) has not shown any of these problems.

\section{DISCUSSION}

The evidence is dominated by three products, QuikClot Combat Gauze (QCG), HemCon (HCG) and Celox (Cx), which have all been shown to be effective in both preclinical and clinical studies.

\section{QuikClot Combat Gauze}

QuikClot Combat Gauzehad the largest number of uses within the study $(n=390)$, with 17 preclinical and three clinical studies, 


\begin{tabular}{|c|c|c|c|c|c|c|}
\hline $\begin{array}{l}\text { Lead author, } \\
\text { year }\end{array}$ & $\begin{array}{l}\text { Background } \\
\text { Location/type of injuries } \\
\text { Type of bleeding }\end{array}$ & $\begin{array}{l}\text { Subject } \\
\text { (n) }\end{array}$ & Test agents & Survival (\%) & $\begin{array}{l}\text { Initial } \\
\text { haemostasis } \\
\text { achieved }\end{array}$ & Rebleeding \\
\hline $\begin{array}{l}\text { Wedmore et } a l^{24} \\
2006\end{array}$ & $\begin{array}{l}\text { Review of combat usage by US SOF in Iraq and Afghanistan. Application time and pressure not } \\
\text { given. } \\
35 \text { extremities, } 25 \text { trunk/groin/buttocks/abdomen } \\
7 \text { arterial; } 33 \text { venous; } 24 \text { unknown }\end{array}$ & 64 & HCG $(n=64)$ & - & $97 \%$ & $1.5 \%$ \\
\hline $\begin{array}{l}\text { Brown et a }\left.\right|^{25} \\
2007\end{array}$ & $\begin{array}{l}\text { Case series of paramedic use. Application time and pressure 'not standardised' } \\
13 \text { head/neck/face injuries; } 18 \text { extremities; } 1 \text { abdomen; } 1 \text { axial; } 1 \text { chest } \\
12 \text { arterial; } 13 \text { venous; } 9 \text { unknown }\end{array}$ & 34 & HCG $(n=34)$ & - & $\begin{array}{l}79 \%(27 / 34) \\
6 / 7 \text { failures } \\
\text { attributed to user } \\
\text { error }\end{array}$ & - \\
\hline $\begin{array}{l}\text { Cox et } a l^{26} \\
2009\end{array}$ & $\begin{array}{l}\text { Retrospective case series of battlefield/field hospital uses of HemCon and QuikClot from notes. } \\
\text { Application time and pressure not given. } 34 \text { patients treated in ED; } 8 \text { on the battlefield } \\
26 \text { trunk (including intra-abdominal/thoracic); } 7 \text { extremities } \\
7 \text { arterial; } 8 \text { venous; } 8 \text { combined; } 4 \text { solid organ; } 15 \text { indeterminate }\end{array}$ & 41 & HCG $(n=40)$ & 95 & $>95 \%$ & - \\
\hline $\begin{array}{l}\text { Ran et } a l^{27} \\
2010\end{array}$ & $\begin{array}{l}14 \text { uses of QuikClot from the battlefield. Application followed by a 'regular dressing and pressure' } \\
10 \text { head/neck/axilla/buttocks/abdomen/back/pelvis; } 4 \text { extremities } \\
13(93 \%) \text { blast or gunshot } \\
3 \text { failures were attributed to severe soft tissue and vascular injuries. }\end{array}$ & 14 & QCG $(n=14)$ & $\begin{array}{l}93 \text { (though not } \\
\text { explicitly stated) }\end{array}$ & $79 \%(11 / 14)$ & - \\
\hline $\begin{array}{l}\text { Pozza et al }{ }^{28} \\
2011\end{array}$ & $\begin{array}{l}21 \text { soldiers with gunshots treated with Celox at a field hospital. Celox applied followed by gauze } \\
\text { and pressure for } 2 \text { min } \\
17 \text { extremities; } 1 \text { neck } \\
15 \text { already had tourniquets applied }\end{array}$ & 21 & $C x(n=21)$ & - & $86 \%(18 / 21)$ & - \\
\hline $\begin{array}{l}\text { King and } \\
\text { Schreiber }^{29} \\
2011\end{array}$ & $\begin{array}{l}2 \text { case reports, one from battlefield IED explosion, one civilian multiple gunshot wounds. Application } \\
\text { time and pressure not given } \\
1 \text { extremity; } 1 \text { groin } \\
1 \text { venous; } 1 \text { unknown }\end{array}$ & 2 & MRDH $(n=2)$ & $100 \%$ & $100 \%$ & - \\
\hline $\begin{array}{l}\text { Tan and Bleeker }{ }^{30} \\
2011\end{array}$ & $\begin{array}{l}\text { Review of use of Celox in Netherlands (HEMS) and Afghanistan. After application, manual pressure } \\
\text { applied for } 5 \text { min then covered with an occlusive bandage. } 3 \text { prehospital; } 4 \text { battlefield } \\
2 \text { extremities; } 2 \text { head/neck; } 3 \text { junctional }\end{array}$ & 7 & $C x(n=7)$ & - & $86 \%(6 / 7)$ & - \\
\hline $\begin{array}{l}\text { King }^{31} \\
2011\end{array}$ & $\begin{array}{l}\text { Review of usage by surgical team in a forward operating theatre in Iraq. Application time and } \\
\text { pressure not given } \\
\text { Multiple injuries including intra-abdominal organ lacerations, vena cava laceration as well as } \\
\text { peripheral injuries } \\
68 \% \text { penetrating injuries, } 45 \% \text { blast injuries }\end{array}$ & 19 & MRDH $(n=19)$ & - & $84 \%$ & $19 \%$ \\
\hline $\begin{array}{l}\text { Travers et al } \beta^{32} \\
2016\end{array}$ & $\begin{array}{l}30 \text { uses of QuikClot QCG by prehospital clinical teams. Application time and pressure not given } \\
15 \text { penetrating wounds (including } 1 \text { gunshot wound); } 4 \text { falls; } 3 \text { RTC } \\
16 \text { head/neck injuries } \\
19 \text { arterial bleeds; } 6 \text { venous; } 5 \text { unknown }\end{array}$ & 30 & QCG $(n=30)$ & 80 & $93 \%$ & $73 \%$ \\
\hline $\begin{array}{l}\text { Shina et } a \beta^{\beta 3} \\
2015\end{array}$ & $\begin{array}{l}122 \text { cases from battlefield injuries. Application time and pressure not given } \\
104 \text { penetrating injuries; } 4 \text { blunt; } 14 \text { combined } \\
37 \text { junctional wounds; } 63 \text { extremities; } 4 \text { head/neck; } 10 \text { chest; } 1 \text { abdomen }\end{array}$ & 122 & QCG $(n=122)$ & 93.2 & $90.7 \%$ & - \\
\hline $\begin{array}{l}\text { Hatamabadi } \\
\text { et } a l^{34} \\
2015\end{array}$ & $\begin{array}{l}\text { RCT of Celox versus standard gauze in prehospital penetrating limb trauma. Application time and } \\
\text { pressure not given } \\
\text { Predominantly peripheral penetrating injuries greater than } 3 \mathrm{~cm}\end{array}$ & 160 & $\begin{array}{l}\text { CX }(n=80) \\
\text { SG }(n=80)\end{array}$ & - & $\begin{array}{l}61.2 \% \\
38.8 \% \\
\text { (haemostasis in } \\
<5 \mathrm{~min} \text { ) }\end{array}$ & - \\
\hline
\end{tabular}

.CX, Celox; ED, emergency department; HCG, HemCon Chitogauze/Chitoflex/RTS; HEMS, Helicopter Emergency Medical Services; IED, improvised explosive device; MRDH, Modified Rapid Deployment Hemostat; QCG, QuikClot Combat Gauze; RCT, randomised controlled trial; RTC, road traffic collision; SG, standard gauze; SOF, Special Operations Forces.

including a case series of 122 battlefield uses by the Israeli Defence Force.

It performs the best in 10 of the 31 preclinical studies in this review, equal to Celox. Combined with the large number of uses, this shows conclusively that QuikClot Combat Gauzeis effective, both preclinically and in battlefield or prehospital clinical use.

\section{HemCon}

While HemCon has fewer individual uses $(\mathrm{n}=281)$ than the other two market leaders, it has been shown to be effective in numerous preclinical studies and performed the best in 11 of these. It is used in three clinical studies, one of which is a large case series documenting 64 instances of use, with haemostasis being achieved in $97 \%$ of cases.

\section{Table 2 Instances of haemostatic use in studies}

\begin{tabular}{ll}
\hline Haemostatic agent & $\begin{array}{l}\text { Instances of use } \\
(\mathbf{n})\end{array}$ \\
\hline HemCon & 258 \\
\hline Celox & 310 \\
QuikClot Combat Gauze & 390 \\
\hline
\end{tabular}

\section{Celox}

Celox was most effective in 10 of the 31 preclinical studies. Celox is also the product used in the only randomised controlled trial (RCT) of a haemostatic agent; this 2015 study $^{34}$ shows that it is significantly better than pressure dressing along at achieving initial haemostasis (measured at $5 \mathrm{~min}$ ), in prehospital, civilian haemorrhage $(61.2 \%$ vs $38.8 \%, \mathrm{p}<0.01)$. They also found that its use led to significantly lower blood loss and quicker time to haemostasis.

This study, carried out in 2015 and based in Tehran, Iran, randomised patients who had suffered a penetrating limb injury on arrival at an emergency department. Any limb wound over 3

Table 3 Summary of product performance against defined outcomes (survival, initial haemostasis and rebleeding) in preclinical and clinical studies

\begin{tabular}{ll} 
Haemostatic agent & $\begin{array}{l}\text { Effective in number of } \\
\text { studies }\end{array}$ \\
\hline Celox & 17 \\
\hline HemCon & 18 \\
\hline QuikClot Combat Gauze & 20 \\
\hline
\end{tabular}


Table 4 Results of studies including head-to-head comparisons of the three market-leading products

\begin{tabular}{ll}
\hline Head to head & Most effective product \\
\hline Three-way & $2 \times$ Celox \\
& $2 \times$ QuikClot Combat Gauze \\
\hline Celox versus QuikClot Combat Gauze & $3 \times$ Celox \\
Celox versus HemCon & $1 \times$ Celox \\
& $1 \times$ HemCon \\
QuikClot Combat Gauze versus HemCon & 2 HemCon \\
\hline
\end{tabular}

$\mathrm{cm}$ was included and they excluded wounds with foreign bodies, patients on anticoagulation or if they had been given blood products or haemostatic agents prior to arrival. The authors justify their use of standard pressure dressings in the control group as this is the current standard of care in prehospital medicine, though it could have been improved by the inclusion of other haemostatics. The study is relatively large $(n=160)$ compared with the other clinical studies on haemostatics and they perform and describe a detailed power calculation. The authors justify their lack of blinding as a pragmatic step. Randomisation was carried out using a block sampling system, which is not further described, but the pretest characteristics of the patients are given and appear comparable. The outcomes used were haemostasis within $5 \mathrm{~min}, 10 \mathrm{~min}$ or after $10 \mathrm{~min}$. Though seemingly arbitrary and sensible, $5 \mathrm{~min}$ is similar to the Kheirabadi model and the other measures fit in with the theory of the 'platinum 10 min.' They use appropriate methods for statistical analysis and give $p$ values for their outcome measures. Overall this is the highest level of evidence for a study of haemostatics currently, being the only RCT comparing a haemostatic to standard dressing and it could only be slightly improved in terms of methodology as described above.

Celox does not have the biggest number of individual uses (QuikClot Combat Gauze holds this accolade), however it still has a large number of uses $(n=332)$ and performs joint best in the studies used in the review. It has been successfully used by the

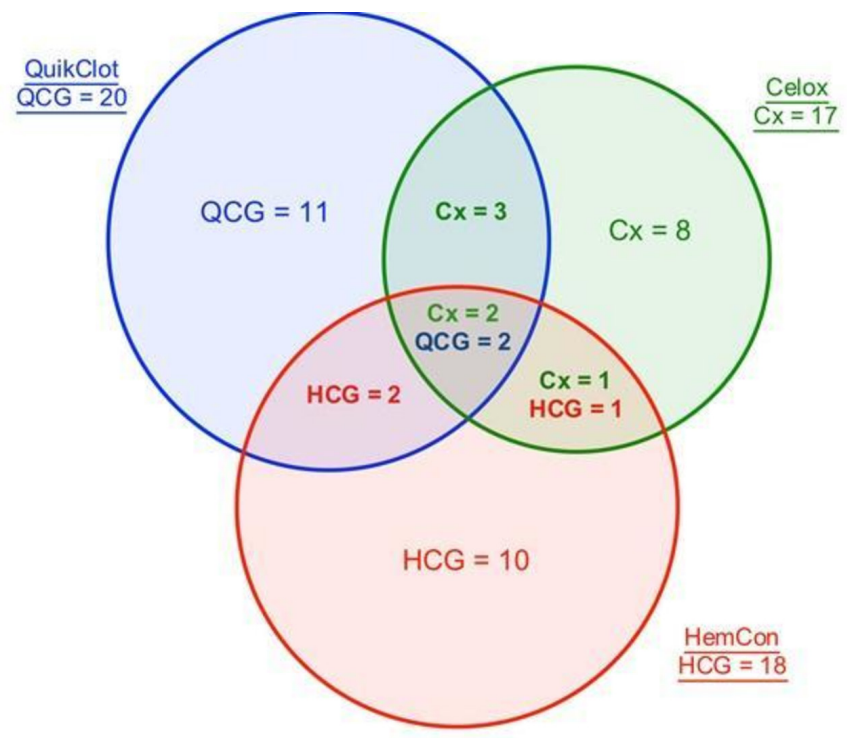

Figure 2 Visual representation of the number of studies in which a market-leading haemostatic was found to be effective, including the number of studies which compared the haemostatics and which was more effective in that comparison. Cx, Celox; HCG, HemCon; QCG, QuikClot Combat Gauze.
UK military, as its standard haemostatic bandage, for the past 10 years in Iraq and Afghanistan, including a number of instances of uses in surgical procedures, ${ }^{37-39}$ as well as the studies in this review.

\section{Other agents}

The dominance of Celox, HemCon and QuikClot Combat Gauze is due to their use by military forces worldwide, especially the US military. They have been used by a number of armed forces and civilian organisations for the past 10 years, including prehospital use by civilian agencies. Because they have proven to be effective in preclinical and clinical use, other products will struggle to challenge their dominance and, therefore, are unlikely to generate their own evidence for efficacy. Several other products have been shown to be effective in arrest of haemorrhage by studies included in this review, including ExcelArrest, BleedArrest, MRDH and Silver Leaf. However, these are typically from a single study showing preclinical effectiveness so require more evidence if they are to be practically considered along with the market-leading products. Topical haemostatics have even been used intrasurgically, leading innovation in surgical haemostatic research.

\section{Comparison of haemostatic agents}

There were no direct head-to-head clinical trials comparing the efficacy of any haemostatic agents, and although there were trials in the preclinical setting comparing the three main agents, ${ }^{40-43}$ they did not identify a clearly superior agent. In the four preclinical studies which directly compared all three agents Celox and QuikClot Combat Gauze were equally effective, with Celox being found to be superior in two cases and QuikClot Combat Gauze being found to be superior in the other two, and HemCon in none. Interestingly, however, when QuikClot Combat Gauze was compared individually with HemCon, HemCon was found to be superior in both of the two studies carried out, raising doubt over which is actually more effective. When Celox was compared with HemCon alone, then Celox was found to be superior in all three of the studies, but when compared with QuikClot Combat Gauze alone, there was one study which found Celox was more effective and one the opposite. The results are therefore reasonably inconclusive about which agent is more effective, although one could make the case that as Celox was found to be better in six out of the nine preclinical trials in which it was compared with other agents, it may be superior. However, further research, particularly in the clinical field, would be helpful in order to assess this claim more fully.

\section{Quality of evidence}

The majority of the studies found in the systematic review were small preclinical animal case series, which under the Oxford Centre for Evidence-Based Medicine ${ }^{44}$ levels of evidence are level 4. This means that they are of limited value on their own, but taken together are informative as to efficacy of the products examined. The clinical relevance of these studies is limited by the fact that they are all animal studies, but provides justification for the use of the products clinically and proof of mechanism. Of the clinical studies, the majority are case series (also level 4), but have clinical relevance in proving the efficacy of the products in humans. The sole RCT is a level 2 study, which is the greatest level of evidence of all the studies in the review, but is limited in relevance by the methods and outcomes that the authors used.

The lack of clear evidence of dominance of one agent may be due to variations in methodology and outcome, as well as the 
small numbers used in individual studies. Although most studies used the Kheirabadi mode ${ }^{22}$ as a loose outline there were variations in the time and pressure applied during application of the haemostatic gauze and other adjuncts (mostly standard gauze or pressure bandages). With regard to outcomes these ranged from survival, estimated blood loss and time to haemostasis, and the results were not always consistent or clear in how they were reported. The field of haemostatic research would benefit from more consistent use of the Kheirabadi model as standardisation.

The various iterations of these dressings studied over the last decade provided a challenge for the reviewers in terms of identifying those appropriate for inclusion. The Celox and HemCon dressings have remained mostly unchanged (except by name), chitosan-based topical dressings with small variations to improve efficacy; Chitogauze, RTS and Chitoflex are examples of the HemCon dressings; Celox and Celox Rapid, the latest version of the Celox chitosan-based products. The QuikClot dressings evolved from a Zeolite-based powder into the versions considered in this review, which use Kaolin as the active substance.

\section{Strengths and limitations}

The key limitation of our study is the quality of the constituent studies used. Most are preclinical, animal-based studies and of the clinical studies only one was an RCT. This is due to ethical and practical issues around prehospital research, especially with major haemorrhage where there is little time for decision-making before treatment. There was also a disparity in the methods and outcomes used by the studies, which made comparison more challenging and meant that a meta-analysis could not be performed. Due to practical reasons we could only use English language papers and this may have meant papers were missed in the search. The dominance of several dressings in the literature was also a factor that may have added bias, but was not ameliorable.

The strengths of this study are the methodology; a systematic review is the highest level of evidence possible within the constraints of the primary literature available. We have included all the available data on current haemostatic dressings with a prehospital capability.

\section{Areas for future research}

A large-scale, randomised trial of all of the products shown to be effective in arresting haemorrhage used in a prehospital setting would be the ideal further study to show more definitively which topical haemostatics.

Although prehospital research can be challenging with issues surrounding consent, randomisation and local logistical guidelines, one possibility could be to carry out a randomised doubleblind study of different haemostatics across different ambulance services. Another possibility would be the recording of prehospital uses and outcomes of haemostatics to a large, retrospective analysis of these data.

\section{CONCLUSIONS}

Topical haemostatic dressings are effective methods of arresting haemorrhage in the prehospital and battlefield environments. This review provides a comprehensive overview of the evidence for topical haemostatic dressings and highlights areas of strength and weakness within this body of knowledge, as well as indicates which haemostatics are best evidenced. The majority of current published literature on haemostatics consists of preclinical case studies with a few clinical case series and only a single clinical RCT.
The studies included show efficacy of a number of haemostatic dressings, with the most positive evidence available for Celox, HemCon and QuikClot dressings against the outcomes of survival, initial haemostasis and rebleeding. Although Celox and QuikClot Combat Gauze have the largest bodies of evidence, HemCon is considered the most effective in several studies and cannot be considered inferior based on the evidence available. These three dressings are the current standard in the field and are likely to remain so, without head-to-head clinical trials involving other products. There are other haemostatics available with less evidence, but these again may prove to be efficacious (or not) with further studies.

Acknowledgements Vanessa Bell and the defence librarians are acknowledged for so expertly searching the literature. Lt Col Pete Williams; Lt Col Dan Stinner, US Army; Capt Giles Nicholes, Capt Jon Catley and Capt Frances Parkes are thanked for the thoughts and ideas they contributed to this review.

Contributors MW and JB are joint first authors; they conducted the experiment and drafted the study. AP contributed to writing the results, discussion and conclusions, as well as assisting in editing and formatting. CW reviewed the study, made additions and corrections, and formatted the paper in a scientific style.

Funding The authors have not declared a specific grant for this research from any funding agency in the public, commercial or not-for-profit sectors.

Competing interests None declared.

Patient consent for publication Not required.

Provenance and peer review Not commissioned; externally peer reviewed.

\section{ORCID iD}

Matthew Welch http://orcid.org/0000-0002-8075-7630

\section{REFERENCES}

1 Porter. Major trauma. Oxford: Oxford University Press, 2010.

2 WHO, 2016. Violence and injury prevention: key facts. Available: http://www.who.int/ violence_injury_prevention/key_facts/en/ [Accessed 5 Aug 2016].

3 Sauaia A, Moore FA, Moore EE, et al. Epidemiology of trauma deaths: a reassessment. J Trauma 1995;38:185-93.

4 Champion HR, Bellamy RF, Roberts CP, et al. A profile of combat injury. J Trauma 2003;54(5 Suppl):S13-19.

5 Eastridge BJ, Mabry RL, Seguin P, et al. Death on the battlefield (2001-2011): implications for the future of combat casualty care. J Trauma Acute Care Surg 2012;73(Suppl 5):S431-7.

6 Cothren CC, Moore EE, Hedegaard HB, et al. Epidemiology of urban trauma deaths: a comprehensive reassessment 10 years later. World J Surg 2007;31:1507-11.

7 Eastridge BJ, Hardin M, Cantrell J, et al. Died of wounds on the battlefield: causation and implications for improving combat casualty care. J Trauma 2011;71(1 Suppl):S4-S8.

8 Frykberg ER. Medical management of disasters and mass casualties from terrorist bombings: how can we cope? J Trauma 2002;53:201-12.

9 de Ceballos JP, Turégano-Fuentes F, Perez-Diaz D, et al. The terrorist bomb explosions in Madrid, Spain - an analysis of the logistics, injuries sustained and clinical management of casualties treated at the closest Hospital. Critical Care 2004;9:104-11.

10 Pizov R, Oppenheim-Eden A, Matot I, et al. Blast lung injury from an explosion on a civilian bus. Chest 1999;115:165-72.

11 Peleg K, Aharonson-Daniel L, Stein M, et al. Israeli trauma group (ITG) gunshot and explosion injuries: characteristics, outcomes and implications for care of terror-related injuries in Israel. Ann Surg 2004;239:311-8.

12 Journal of Special Operations Medicine, 2017. TCCC guidelines for medical personnel. Available: https://www.jsomonline.org/TCCC.html [Accessed $10 \mathrm{Apr} 2017$ ].

13 Joint Service Publication (JSP), 2012. 999: clinical guidelines for operations (CGO). Ministry of defence. Available: https://www.gov.uk/government/publications/jsp-999clinical-guidelines-for-operations [Accessed 20 Mar 2017].

14 Achneck HE, Sileshi B, Jamiolkowski RM, et al. A comprehensive review of topical hemostatic agents: efficacy and recommendations for use. Annals of Surgery 2010;251:217-28

15 Granville-Chapman J, Jacobs N, Midwinter MJ. Pre-hospital haemostatic dressings: a systematic review. Injury 2011;42:447-59.

16 Bennett BL, Littlejohn L. Review of new topical hemostatic dressings for combat casualty care. Mil Med 2014:179:497-514.

17 Grissom TE, Fang R. Topical hemostatic agents and dressings in the prehospital setting. Curr Opin Anaesthesiol 2015;28:210-6. 
18 Kheirabadi BS, Estep SJ, Dubick MA. Assessment of efficacy of new hemostatic agents in a model of extremity arterial hemorrhage in swine. US Army Institute of Surgical Research.

19 Smith AH, Laird C, Porter K, et al. Haemostatic dressings in prehospital care. Emerg Med J 2013;30:784-9.

20 Gegel BT, Austin PN, Johnson AD. An evidence-based review of the use of a combat gauze (QuikClot) for hemorrhage control. Aana J 2013;81:453-8.

21 Pusateri AE, McCarthy SJ, Gregory KW, et al. Effect of a chitosan-based hemostatic dressing on blood loss and survival in a model of severe venous hemorrhage and hepatic injury in swine. The Journal of Trauma: Injury, Infection, and Critical Care 2003:54:177-82.

22 Kheirabadi BS, Arnaud F, McCarron R, et al. Development of a standard swine hemorrhage model for efficacy assessment of topical hemostatic agents. J Trauma 2011;71(1 Suppl):S139-S146.

23 PRISMA. Transparent reporting of systematic reviews and meta-analyses (2015) PRISMA guidelines. Available: http://www.prisma-statement.org/ [Accessed 2 Feb 2016].

24 Wedmore I, McManus JG, Pusateri AE, et al. A special report on the chitosanbased hemostatic dressing: experience in current combat operations. J Trauma 2006;60:655-8

25 Brown MA, Daya MR, Worley JA. Experience with chitosan dressings in a civilian EMS system. J Emerg Med 2009;37:1-7.

26 Cox ED, Schreiber MA, McManus J, et al. New hemostatic agents in the combat setting. Transfusion 2009:49:248S-55.

27 Ran Y, Hadad E, Daher S, et al. QuikClot combat gauze use for hemorrhage control in military trauma: January 2009 Israel defense force experience in the Gaza Strip-A preliminary report of 14 cases. Prehospital and Disaster Medicine 2010:25:584-8

28 Pozza M, Millner RW, Celox MRW. Celox (chitosan) for haemostasis in massive traumatic bleeding: experience in Afghanistan. Eur J Emerg Med 2011;18:31-3.

29 King DR, Schreiber MA. The mRDH bandage provides effective hemostasis in trauma and surgical hemorrhage. J Trauma 2011;71:S167-S170.

30 Tan E, Bleeker CP. Field experience with a chitosan-based haemostatic dressing. Med Corps Int Forum 2011;3:11-15.

31 King DR. Thirty consecutive uses of a hemostatic bandage at a US army combat support hospital and forward surgical team in operation Iraqi freedom. J Trauma 2011;71:1775-8.
32 Travers S, Lefort H, Ramdani E, et al. Hemostatic dressings in civil prehospital practice: 30 uses of QuikClot QCG. European journal of emergency medicine 2016;23.

33 Shina A, Lipsky AM, Nadler R, et al. Prehospital use of hemostatic dressings by the Israel defense Forces medical Corps: a case series of 122 patients. J Trauma Acute Care Surg 2015;79(4 Suppl 2):S204-S209.

34 Hatamabadi HR, Asayesh Zarchi F, Kariman H, et al. Celox-Coated gauze for the treatment of civilian penetrating trauma: a randomized clinical trial. Trauma Monthly 2015:20:1-5.

35 Kheirabadi BS, Mace JE, Terrazas IB, et al. Safety evaluation of new hemostatic agents, Smectite granules, and Kaolin-Coated gauze in a vascular injury wound model in swine. J Trauma 2010;68:269-78.

36 Rhee P, Brown C, Martin M, et al. QuikClot use in trauma for hemorrhage control: case series of 103 documented uses. J Trauma 2008:64:1093-9.

37 Millner RW, Lockhart AS, Bird H, et al. A new hemostatic agent: initial life-saving experience with Celox (chitosan) in cardiothoracic surgery. Ann Thorac Surg 2009;87:e13-14

38 Arul GS, Bowley DM, DiRusso S. The use of Celox gauze as an adjunct to pelvic packing in otherwise uncontrollable pelvic haemorrhage secondary to penetrating trauma. J R Army Med Corps 2012;158:331-4.

39 Muzzi L, Tommasino G, Tucci E, et al. Successful use of a military haemostatic agent in patients undergoing extracorporeal circulatory assistance and delayed sternal closure. Interact Cardiovasc Thorac Surg 2012;14:695-8.

40 Kheirabadi BS, Scherer MR, Estep JS, et al. Determination of efficacy of new hemostatic dressings in a model of extremity arterial hemorrhage in swine. J Trauma 2009;67:450-60.

41 Littlejohn LF, Devlin JJ, Kircher SS, et al. Comparison of Celox-A, ChitoFlex, WoundStat, and combat gauze hemostatic agents versus standard gauze dressing in control of hemorrhage in a swine model of penetrating trauma. Acad Emerg Med 2011;18:340-50

42 Rall JM, Cox JM, Songer AG, et al. Comparison of novel hemostatic dressings with QuikClot combat gauze in a standardized swine model of uncontrolled hemorrhage. Journal of Trauma and Acute Care Surgery 2013;75(2 Suppl 2):S150-S156.

43 Satterly S, Nelson D, Zwintscher N, et al. Hemostasis in a noncompressible hemorrhage model: an end-user evaluation of hemostatic agents in a proximal arteria injury. J Surg Educ 2013;70:206-11.

44 OCEBM Levels of Evidence Working Group. The Oxford Levels of Evidence 2". Available: http://www.cebm.net/index.aspx?o=5653 